\title{
CÁC YẾU TỐ TRONG THỰC TIẼ̃N QUẢN TRI NGUỒN NHÂN LỰC ẢNH HƯỞNG ĐẾN CAM KẾT TÌNH CẢM CỦA NHÂN VIÊN TẠI CÔNG TY CỔ PHẨN THƯỚNG MẠI SÀI GÒN - SATRA
}

\author{
MAI THANH HÙNG, ĐẶNG TRUNG KIÊN \\ Khoa Thương mại \& Du lịch, Trương Đại Học Công Nghiệp thành phố Hồ Chí Minh \\ maithanhhung@iuh.edu.vn
}

Tóm tắt. Bài báo này nhằm mục đích nâng cao hiệu quả thực tiễn quản lý nguồn nhân lực để tăng sự cam kết tình cảm của nhân viên với Công ty Cổ phần Satra và xác định các thành phần ảnh hưởng đến cam kết tình cảm của nhân viên với tổ chức. Dựa trên phương pháp phân tích dữ liệu như phân tích Cronbach's alpha, phân tích EFA và phân tích hồi quy bội từ đó đo lường mức độ ảnh hưởng các yếu tố đến sự cam kết tình cảm của nhân viên đối với Công ty Cổ phần Satra

Các kết quả thu được từ nghiên cứu này góp phần bổ sung vào thực tiễn quản lý, giúp các nhà quản trị hiểu biết rõ hơn về công tác quản trị nguồn nhân lực, tạo được sự gắn kết của nhân viên với tổ chức để duy trì nguồn lực cho doanh nghiệp.

Từ khóa: Thực tiễn quản trị nguồn nhân lực, Cam kết tình cảm của nhân viên, Công ty Cổ phần Satra.

\section{THE FACTORS IN THE PRACTICE OF HUMAN RESOURCES AFFECT THE SACRIFICE OF EMPLOYEES IN SAI GON COMMERCIAL JOINT STOCK COMPANY - SATRA}

\begin{abstract}
This article aims to improve the effectiveness of human resource management practices in order to increase the emotional commitment of employees to Satra Joint Stock Company and identify the components that affect the employee's emotional commitment. Based on data analysis methods such as Cronbach's alpha analysis, EFA analysis and multiple regression analyzes, it measures the influence of factors on the emotional commitment of employees to SATRA.

The results from this research add to the management practice, giving managers a better understanding of human resource management, creating a cohesive relationship between employees and the organization. Maintain resources for the business.
\end{abstract}

Key words: Practice of human resources, Commitment of employees, Satra Corporation.

\section{1. ĐẶT VẤn ĐỀ}

Công tác quản trị nguồn nhân lực là rất quan trọng ở bất kỳ mỗi cơ quan tổ chức nào, đặc biệt là trong giai đoạn hiện nay tình hình nhân sự trong ngành bán lẻ thật rất cần thiết, bởi vì thị truờng cạnh tranh với nhau không những bởi sản phẩm dịch vụ mà là bởi yếu tố con người. Nhiều doanh nghiệp bán lẻ hiện nay xem con người là tài sản quý giá nhằm thu hút nhân tài từ các đối thủ cạnh tranh và làm thế nào để nhân sự Công ty Cổ phần Satra cam kêt gắn bó dài lâu để ổn định phát triển. Việc thực hiện tốt công tác quản trị nguồn nhân lực sẽ giúp các nhà quản lý duy trì được nguồn nhân lực chất lượng cao tại doanh nghiệp cũng như làm tăng sự cam kết tình cảm của nhân viên và hạn chế được việc nhân viên của mình rời bỏ doanh nghiệp. Đây cũng là đề tài được nghiên cứu bởi nhiều chuyên gia trong nước và các nhà nghiên cứu nổi tiếng ở nước ngoài như Các nghiên cứu của Mowday và cộng sự (1982), Allen và Mayer (1990), Hackett và cộng sự (1994), Herscovitch và Mayer (2002), Al Kahtani (2004), Shaw và cộng sự (2003), Yousef (2000) đều chỉ ra rằng nhân tố chính ảnh hưởng đến quá trình và kết quả làm việc của nhân viên chính là sự gắn bó với tổ chức. Các nghiên cứu trên thế giới chỉ ra rằng khi tổ chức thực hiện tốt các công tác quản trị nguồn nhân lực sẽ mang lại hài lòng cho nhân viên và từ đó họ cống hiến nhiều hơn cho tổ chức.

Tại Công ty Cổ phần Satra công tác quản trị nguồn nhân lực chưa thực sự được quan tâm nhiều về quản trị nguồn nhân lực hiện đại còn nhiều hạn chế. Công ty Cổ phần Satra hiện tại đang nằm trong top 100 doanh nghiệp lớn tại TP.HCM tuy nhiên Satra hiện đang hoạt động trong một thị trường kinh doanh khốc liệt với hàng loạt các hệ thống siêu thị quốc tế như Big $\mathrm{C}$, Metro, Coopmart, Vinmart...và sắp tới là hàng loạt nhà bán lẻ nổi tiếng khác. Trong khi đó, về vấn đề nguồn nhân lực, nhân viên chưa gắn kết lâu, nhiều nhân viên nghỉ việc trong thời gian dài, nguyên do là công tác nghiên cứu quản trị nguồn nhân lực chưa tốt. Cụ thể 
như Satra chưa có bảng phân tích công việc cho từng đối tượng nhân viên, chưa có bảng mô tả công việc cụ thể rõ ràng, công tác tuyển dụng còn chưa minh bạch, chưa có tiêu chuẩn tuyển dụng ở vị trí cụ thể, thu nhập của người lao động trung bình còn rất thấp, công tác đào tạo gần như hơn 5 năm qua chưa được thực hiện. Bên cạnh đó, trong lĩnh vực phân phối và bán lẻ nói chung cũng như tại Satra chưa nghiên cứu tác động thực tiễn quản trị nguồn nhân lực đến cam kết tình cảm của nhân viên.

Vì thế từ các nghiên cứu trước đây của thế giới và thực tiễn quản trị nhân sự tại Công ty Cổ phần Satra thì đề tài " Các yếu tố tố trong thực tiễn quản trị nguồn nhân lực ảnh hưởng đến sự cam kết tình cảm của nhân viên tại Công ty Cổ phẩn Satra" là cần thiết, giúp ích cho Ban lãnh đạo biết được thành phần nào tác động mạnh nhất đển cam kết tình cảm của nhân viên, nhằm nâng cao sự cam kết tình cảm của nhân viên đối với Satra.

\section{PHƯƠNG PHÁP NGHIÊN CÚU}

Trong giới hạn của một bài báo, các dữ liệu thu thập được xử lý đơn giản, phục vụ cho việc giải thích kết quả. Vì thế phương pháp được lựa chọn là phương pháp phân tích thống kê mô tả. Kỹ thuật xử lý dữ liệu chính được lựa chọn là kỹ thuật phân tích bằng máy tính.

Nghiên cứu được thực hiện gồm hai phương pháp: Phương pháp nghiên cứu định tính và phương pháp nghiên cứu định lượng.

Trong đó, nghiên cứu định tính được thực hiện thông qua kỹ thuật thảo luận nhóm tập trung.

Nghiên cứu định lượng thực hiện bằng kỹ thuật thu thập thông tin trực tiếp bằng phiếu khảo sát trực tiếp đối tượng nghiên cứu. Để tìm hiểu về những yếu tố ảnh hưởng đến sự cam kết của nhân viên tại Công ty Cổ phần Satra, thang đo các nhân tố ảnh hưởng đến được kiểm định thông qua hệ số tin cậy Cronbach's Alpha, phân tích nhân tố khám phá EFA, thông qua các phần mềm xử lý số liệu thống kê SPSS .

\section{Mô tả mẫu nghiên cứu}

Tổng cộng có 300 phiếu khảo sát. Sau khi thu thập và kiểm tra 2 phiếu bị loại do có nhiều câu để trống không trả lời hoặc các câu trả lời không hợp lý, còn lại 298 phiếu khảo sát đạt yêu cầu được nhập liệu làm cơ sở cho phân tích dữ liệu.

Bảng 1: Bảng mô tả mẫu theo đặc điểm giới tính

\begin{tabular}{|l|l|l|l|}
\hline \multicolumn{2}{|l|}{ Phân bố mẫu theo } & Số lượng & \% trong mẫu \\
\hline \multirow{2}{*}{ Giới tính } & Nam & 206 & 69,1 \\
\cline { 2 - 4 } & Nữ & 92 & 30,9 \\
\hline & Tổng cộng & 298 & 100,0 \\
\hline
\end{tabular}

Về giới tính: Số người nam tham gia trả lời là 206 người chiếm 69,1\%, số người nữ tham gia trả lời là 92 người chiếm tỷ lệ $30,8 \%$. Số lượng cán bộ nhân viên nam chiếm tỷ lệ cao hơn nữ.

Bảng 2: Bảng mô tả mẫu khảo sát theo độ tuổi

\begin{tabular}{|l|l|l|l|}
\hline \multicolumn{2}{|l|}{ Phân bố mẫu theo } & Số lượng & \% trong mẫu \\
\hline \multirow{4}{*}{ Độ tuổi } & Từ $21-30$ tuổi & 113 & 37,9 \\
\cline { 2 - 4 } & Từ $31-40$ tuổi & 98 & 32,9 \\
\cline { 2 - 4 } & Trên 40 tuổi & 87 & 29,2 \\
\cline { 2 - 4 } & Tổng cộng & 298 & 100,0 \\
\hline
\end{tabular}

Về độ tuổi: Độ tuổi từ 21- 30 có tổng cộng 113 người chiếm tỷ lệ $37,9 \%$, độ tuổi từ 30 đến 40 có tổng cộng là 98 người chiếm tỷ lệ 32,9\%, ở độ tuổi trên 40 có 87 người chiếm tỷ lệ $29,25 \%$.

Bảng 3: Bảng mô tả mẫu khảo sát theo trình độ học vấn

\begin{tabular}{|l|l|l|l|}
\hline \multicolumn{2}{|l|}{ Phân bố mẫu theo } & Số lượng & \% trong mẫu \\
\hline \multirow{4}{*}{ Trình độ học vấn } & Cao đẳng & 60 & 20,1 \\
\cline { 2 - 4 } & Đại học & 223 & 74,8 \\
\cline { 2 - 4 } & Trên đại học & 15 & 5,1 \\
\cline { 2 - 4 } & Tổng cộng & 298 & 100,0 \\
\hline
\end{tabular}

Về trình độ học vấn: Đối trình độ cao đẳng có 60 người chiếm 20,1\%, ở trình độ đại học có tổng cộng 223 người chiếm tỷ lệ $74,8 \%$, ở trình độ trên đại học có 15 người chiếm tỷ lệ $5,1 \%$. 
Bảng 4: Bảng mô tả mẫu khảo sát theo công việc

\begin{tabular}{|l|l|l|l|}
\hline \multicolumn{2}{|l|}{ Phân bố mẫu theo } & Số lượng & \% trong mẫu \\
\hline \multirow{4}{*}{ Công việc } & Nhân viên & 215 & 72,4 \\
\cline { 2 - 4 } & Tổ trưởng/chuyên môn & 45 & 15,1 \\
\cline { 2 - 4 } & Quản lý & 38 & 12,5 \\
\cline { 2 - 4 } & Tổng cộng & 298 & 100,0 \\
\hline
\end{tabular}

Về công việc: Kết quả cho thấy đối với những người có vị trí công tác là nhân viên tổng cộng 215 người chiếm tỷ lệ $72,4 \%$, những người là tổ trưởng/chuyên môn là 45 người chiếm tỷ lệ $15,1 \%$, những người là quản lý là 38 người chiếm tỷ lệ $12,5 \%$.

\section{CƠ SỞ LÝ LUẬN VÀ MÔ HÌNH NGHIÊN CÚU}

\subsection{Cơ sở lý luận:}

\subsubsection{Các khái niệm}

Quản trị nguồn nhân lực là hệ thống các triết lý, chính sách và hoạt động chức năng về thu hút, đào tạo phát triển và duy trì con người của một tổ chức nhằm đạt kết quả tối ưu cho cả tổ chức lẫn nhân viên (Trần Kim Dung, 2011).

Quản trị nguồn nhân lực là một loạt những quyết định tổng hợp hình thành nên mối quan hệ về công việc. Chất lượng của những quyết định đó góp phần trực tiếp vào năng lực của tổ chức và của nhân viên để đạt những mục tiêu đề ra (George, 2002).

Theo nghiên cứu của Ilies, R., \& Judge, T. A. (2003) thì sự cam kết được định nghĩa như là sự sẵn sàng nỗ lực hết mình vì sự phát triển của tổ chức, đồng nhất mục tiêu của tổ chức với mục tiêu của chính mình. Còn theo Allen và Meyer (1990) thì sự cam kết của nhân viên với tổ chức là một trạng thái tâm lý buộc chặt cá nhân với tổ chức, liên hệ mật thiết đến quyết định có tiếp tục là thành viên của tổ chức hay không.

3.1.2 Các yếu tố trong thực tiễn quản trị nguồn nhân lực ảnh hưởng đến cam kết tình cảm với tổ chức Theo Singh (2004), thực tiễn quản trị nguồn nhân lực của Ấn Độ gồm có bảy thành phần với những nội dung chính: Xác định công việc, Tuyển dụng, Đào tạo, Đánh giá nhân viên, Hoạch định nghề nghiệp và Cơ hội thăng tiến, Thu hút nhân viên tham gia tích cực vào các hoạt động, Đãi ngộ về lương, thưởng.

Trần Kim Dung (2011), đã đề nghị thực tiễn quản trị nguồn nhân lực trong các doanh nghiệp Việt Nam có 9 thành phần. Ngoài 6 thành phần căn bản thuộc các chức năng nghiệp vụ chính của quản trị nguồn nhân lực: xác định nhiệm vụ, công việc; thuhút, tuyển chọn; đào tạo; đánh giá kết quả làm việc của nhân viên; quản lý lương thưởng; phát triển quan hệ lao động; còn có ba thành phần: thống kê nhân sự; thực hiện quy định Luật pháp; và khuyến khích thay đổi

Theo Allen và Meyer (1991) thì sự cam kết của nhân viên với tổ chức là một trạng thái tâm lý buộc chặt cá nhân với tổ chức, liên hệ mật thiết đến quyết định có tiếp tục là thành viên của tổ chức hay không

\subsection{CÁC GIẢ THUYẾT NGHIÊN CỬU VÀ MÔ HİNH NGHIÊN CÚU ĐỀ XUẤT}

\subsubsection{Sự cam kết tình cảm của nhân viên theo các yếu tố thành phần}

Qua tham khảo các nghiên cứu đã nêu trên và nhiều nghiên cứu trước đây, tác giả dựa vào cơ sở lý thuyết là nghiên cứu của Singh (2004) về thực tiễn quản trị nguồn nhân lực. Bên cạnh đó, khái niệm về cam kết được sử dụng theo quan điểm của Allen và Mayer (1991), đồng thời tham khảo thêm các mô hình đã nghiên cứu trước ở Việt Nam, tác giả nhận thấy các biến trong mô hình gốc của Singh và cộng sự, cùng mô hình nghiên cứu của Trần Kim Dung (2011), phù hợp trong việc nghiên cứu các yếu tố ảnh hưởng đến cam kết tình cảm của nhân viên với doanh nghiệp trong công ty Satra. Các yếu tố thành phần ảnh hưởng đến sự cam kết tình cảm của Satra bao gồm:

(1) Phân tích công việc: là quá trình nghiên cứu nội dung công việc nhằm xác định điều kiện tiến hành, các nhiệm vụ, trách nhiệm, quyền hạn khi thực hiện công việc và các phẩm chất, kỹ năng nhân viên cần thiết phải có để thực hiện tốt công việc. Phân tích công việc có ý nghĩa quan trọng và là công cụ cơ bản nhất trong mọi giai đoạn của quản trị nguồn nhân nhân lực

(2) Tuyển dụng: là quá trình sàng lọc các ứng viên có được sau quá trình chiêu mộ theo các tiêu chuẩn cụ thể, phù hợp với yêu cầu công việc của công ty và quyết định sử dụng họ. Yêu cầu công việc được xác định cụ thể qua quá trình phân tích công việc và được thể hiện thông qua bảng mô tả công việc và bảng tiêu chuẩn công việc. Việc tuyển dụng có thể thực hiện bên trong hoặc bên ngoài doanh nghiệp 
(3) Định hướng và phát triển: là quá trình liên tục khám phá về bản thân của mỗi người về các phương diện như tài năng, các giá trị động viên và các yêu cầu.Nghiên cứu định hướng và phát triển nghề nghiệp giúp cho mỗi người phát hiện ra cáckhả năng nghề nghiệp, đưa ra quyết định chọn lựa nghề nghiệp đúng đắn và có kế hoạch đầu tư vào giáo dục, đào tạo chính xác, tiết kiệm.

(4) Đào tạo và phát triển: Huấn luyện đào tạo, phát triển là quá trình giúp con người tiếp thu những kiến thức, học các kỹ năng mới và thay đổi các quan điểm hay hành vi và nâng cao khảnăng thực hiện công việc của cá nhân.

(5) Đánh giá kết quả làm việc của nhân viên: Cung cấp các thông tin phản hồi cho nhân viên biết mức độ thực hiện công việc của họ so với các tiêu chuẩn mẫu và so với các nhân viên khác, giúp nhân viên điều chỉnh, sửa chữa các sai lầm trong quá trình làm việc, kích thích động viên nhân viên thông qua những điều khoản về đánh giá, ghi nhận và hỗ trợ, cung cấp các thông tin làm cơ sở cho các vấn đề đào tạo, trả lương, khen thưởng, thuyên chuyển nhân viên, cải tiến cơ cấu tổ chức v.v...

(6) Trả công lao động: Sự trả công được hiểu là tiền lương, hoặc lương bổng cơ bản, bình thường hay tối thiểu và mọi thứ lợi ích, phụ khoản khác, được trả trực tiếp hay gián tiếp bằng tiền hay hiện vật, mà người sử dụng lao động trả cho người lao động theo việc làm của người lao động. (Trần Kim Dung, 2011).

(7) Quản lý và thu hút nhân viên: là hoạt động của doanh nghiệp mà quá trình nhà quản lý sử dụng các biện pháp gắn nhân viên vào với cơ cấu và hoạt động của tổ chức, các nhân viên được tham gia vào quá trình ra quyết định thay vì chỉ làm theo quyết định của cấp trên

\subsubsection{Mô hình nghiên cứu đề xuất}

Trên cơ sở phân tích các yếu tố ảnh hưởng đến sự cam kết tình cảm của nhân viên với tổ chức ở trên, tác giả đề xuất mô hình nghiên cứu các yếu tố ảnh hưởng đến cam kết tình cảm của nhân viên tại công ty Satra như sau:

\begin{tabular}{|l|}
\hline Phân tích công việc \\
\hline \hline Tuyển dụng \\
\hline Định hướng và phát triển nghề nghiệp \\
\hline Đào tạo và phát triển \\
\hline Trả công lao động \\
\hline Đánh giá kết quả làm việc \\
\hline Thực tiễn quản lý và thu hút nhân viên
\end{tabular}

\subsubsection{Các giả thuyết nghiên cứu}

Hình 1: Mô hình nghiên cứu tác giả đề xuất

- Giả thuyết H1: Phân tích công việc hiệu quả ảnh hưởng đến mức độ cam kết tình cảm của cán bộ nhân viên.

- Giả thuyết H2: Tuyển dụng lao động hiệu quả ảnh hưởng đến mức độ cam kết tình cảm của cán bộ nhân viên.

- Giả thuyết H3: Định hướng và phát triển nghề nghiệp hiệu quảảnhhưởng đến đến mức độ cam kết tình cảm của cán bộ nhân viên.

- Giả thuyết H4: Đào tạo và phát triển hiệu quả ảnh hưởng đến mức độ cam kết tình cảm của cán bộ nhân viên.

- Giả thuyết H5: Trả công lao động hiệu quả ảnh hưởng đến mức độ cam kết tình cảm của cán bộ nhân viên.

- Giả thuyết H6: Đánh giá kết quả làm việc hiệu quả của nhân viên ảnhhưởng đến mức độ cam kết tình cảm của cán bộ nhân viên. 
- Giả thuyết H7: Quản lý và thu hút nhân viên vào hoạt động chung hiệu quả ảnh hưởng đến mức độ cam kết tình cảm của cán bộ nhân viên.

\section{KẾT QUẢ NGHIÊN CÚU}

4.1 Kết quả phân tích độ tin cậy của thang đo

\begin{tabular}{|l|c|c|c|c|l|}
\multicolumn{1}{|c|}{$\begin{array}{c}\text { Thang đo } \\
\text { thành phần }\end{array}$} & $\begin{array}{c}\text { Số biến } \\
\text { quan sát } \\
\text { ban đầu }\end{array}$ & $\begin{array}{c}\text { Hệ số } \\
\text { Cronbach's } \\
\text { Alpha }\end{array}$ & $\begin{array}{c}\text { Hệ số tương } \\
\text { quan biến } \\
\text { tồng }\end{array}$ & $\begin{array}{c}\text { Hệ số } \\
\text { Cronbach's } \\
\text { Alpha nếu } \\
\text { loại biến }\end{array}$ & $\begin{array}{c}\text { Số biến } \\
\text { quan sát } \\
\text { còn lại }\end{array}$ \\
\hline Phân tích công việc & 5 & 0,892 & $\geq 0,745$ & $\leq 0,854$ & 4 \\
\hline Tuyến dụng & 4 & 0,915 & $\geq 0,787$ & $\leq 0,880$ & 4 \\
\hline $\begin{array}{l}\text { Định hướng và phát triển } \\
\text { nghề nghiẹp }\end{array}$ & 5 & 0,900 & $\geq 0,728$ & $\leq 0,861$ & 4 \\
\hline Đào tạo và phát triến & 4 & 0,814 & $\geq 0,606$ & $\leq 0,707$ & 3 \\
\hline Trả công lao đọng & 6 & 0,873 & $\geq 0,688$ & $\leq 0,828$ & 4 \\
\hline Đánh giá kết quả làm việc & 6 & 0,915 & $\geq 0,768$ & $\leq 0,881$ & 4 \\
\hline $\begin{array}{l}\text { Quản lý và thu hút nhân } \\
\text { viên }\end{array}$ & 4 & 0,848 & $\geq 0,684$ & $\leq 0,760$ & 3 \\
\hline $\begin{array}{l}\text { Cam kết tình cảm nhân viên } \\
\text { với tố chức }\end{array}$ & 5 & 0,672 & $\geq 0,427$ & $\leq 0,593$ & 4 \\
\hline
\end{tabular}

Kết quả ở bảng 5 cho thấy, các thang đo sau khi loại các biến không đạt yêu cầu đều có hệ số tin cậy Cronbach's Alpha lớn hơn 0,6 . Hệ số tương quan biến - tổng của các biến quan sát đều lớn hơn 0,3 . Hệ số Cronbach's Alpha nếu loại biến đều đạt tiêu chuẩn tức là bé hơn hệ số Cronbach's Alpha của thang đo. Vì vậy 26 biến quan sát thuộc thang đo các thành phần và 4 biến quan sát thuộc thang đo cam kết tình cảm cán bộ nhân viên với tổ chức đều đạt độ tin cậy.

\subsection{Kết quả phân tích nhân tố khám phá (EFA)}

Bảng 6 : Bảng kết quả phân tích nhân tố khám phá của thang đo thực tiễn quản trị nguồn nhân lực

\begin{tabular}{|c|c|c|c|c|c|c|c|c|}
\hline \multirow[t]{2}{*}{ Yếu tố } & \multirow[t]{2}{*}{\begin{tabular}{|c|} 
Biến \\
quan sát
\end{tabular}} & \multicolumn{7}{|c|}{ Nhân tố } \\
\hline & & 1 & 2 & 3 & 4 & 5 & 6 & 7 \\
\hline \multirow[t]{4}{*}{ Tuyển dụng } & TDNV3 & .901 & & & & & & \\
\hline & TDNV4 & .885 & & & & & & \\
\hline & TDNV2 & .871 & & & & & & \\
\hline & TDNV1 & .863 & & & & & & \\
\hline \multirow[t]{4}{*}{ Đánh giá kết quả làm việc } & DGNV4 & & .892 & & & & & \\
\hline & DGNV1 & & .891 & & & & & \\
\hline & DGNV3 & & .878 & & & & & \\
\hline & DGNV6 & & .868 & & & & & \\
\hline \multirow{4}{*}{$\begin{array}{l}\text { Định hướng và phát triển nghề } \\
\text { nghiệp }\end{array}$} & DHPT1 & & & .881 & & & & \\
\hline & DHPT2 & & & .874 & & & & \\
\hline & DHPT4 & & & .862 & & & & \\
\hline & DHPT5 & & & .833 & & & & \\
\hline Phân tích công việc & PTCV2 & & & & .869 & & & \\
\hline
\end{tabular}



TİNH CẢM CỦA NHÂN VIÊN TẠI CÔNG TY CỔ PHÂNN THƯƠNG MẠI SÀI GÒN - SATRA

\begin{tabular}{|c|c|c|c|c|c|}
\hline & PTCV5 & .865 & & & \\
\hline & PTCV3 & .860 & & & \\
\hline & PTCV4 & .845 & & & \\
\hline Trả công lao động & TCLD1 & & .857 & & \\
\hline & TCLD4 & & .848 & & \\
\hline & TCLD6 & & .845 & & \\
\hline & TCLD5 & & .823 & & \\
\hline Quản lý và thu hút nhân viên & QLTH2 & & & .886 & \\
\hline & QLTH1 & & & .877 & \\
\hline & QLTH4 & & & .835 & \\
\hline Đào tạo và phát triển & DTPT2 & & & & .870 \\
\hline & DTPT3 & & & & .852 \\
\hline & DTPT4 & & & & .799 \\
\hline Tổng phương sai trích & & 77,1 & & & \\
\hline Hệ số KMO (kiểm định Barle & & 0,78 & & & \\
\hline Múc ýnghĩa (Sig.) & & 0,00 & & & \\
\hline
\end{tabular}

Kết quả cho thấy, có 7 yếu tố được trích ra đúng như mong đợi của nghiên cứu, tất cả 26 biến quan sát đều có hệ số tải nhân tố lớn hơn tiêu chuẩn cho phép (Factor Loading $>0,5$ ). Đồng thời kiểm định Bartlett cho thấy giữa các biến trong tổng thể có mối tương quan với nhau (mức ý nghĩa sig $=0,000<0,05$ ) với hệ số $\mathrm{KMO}=0,7824(0,5<\mathrm{KMO}<1)$. Tổng phương sai trích là 77,194 \% > 50\% có nghĩa là giải thích được $77,194 \%$ sự biến thiên của dữ liệu.

Bảng 7 : Kết quả phân tích EFA đối với thang đo cam kết tình cảm

\begin{tabular}{|c|c|c|}
\hline Yếu tố & Biến quan sát & Yếu tố \\
\hline \multirow{4}{*}{ Cam kết tình cảm } & CKTC1 & 0,521 \\
\hline & CKTC2 & 0,467 \\
\hline & CKTC3 & 0,529 \\
\hline & CKTC4 & 0,501 \\
\hline Tổng phương sai trích & \multicolumn{2}{|l|}{50,469} \\
\hline Hệ số KMO (kiểm định Barlett) & \multicolumn{2}{|l|}{0,721} \\
\hline Múc ý nghĩa (Sig.) & \multicolumn{2}{|l|}{0,000} \\
\hline
\end{tabular}

Kết quả cho thấy, tất cả 4 biến quan sát đều có hệ số tải nhân tố lớn hơn tiêu chuẩn cho phép (Factor loading $>0,5)$. Đồng thời kiểm định Bartlett cho thấy giữa các biến trong tổng thể có mối tương quan với nhau (mức ý nghĩa sig $=0,000<0,05)$ với hệ số $\mathrm{KMO}=0,721(0,5<\mathrm{KMO}<1)$. Tổng phương sai trích là 50,469 có nghĩa là giải thích được $50,469 \%$ sự biến thiên của dữ liệu.

\subsection{Kết quả phân tích hồi qui và kiểm định giả thuyết}

Bảng 8: Kết quả phân tích mô hình hồi qui

\begin{tabular}{|c|c|c|c|c|c|c|c|c|}
\hline & \multirow{2}{*}{ Mô hình } & \multicolumn{2}{|c|}{$\begin{array}{c}\text { Hệ số hồi quy chưa } \\
\text { chuẩn hóa }\end{array}$} & \multirow{2}{*}{$\begin{array}{c}\begin{array}{c}\text { Hệ số hồi } \\
\text { quy đã } \\
\text { chuẩn hóa }\end{array} \\
\text { Beta }\end{array}$} & \multirow{2}{*}{$\mathbf{T}$} & \multirow{2}{*}{ Sig. } & \multicolumn{2}{|c|}{ Thống kê đa cộng tuyến } \\
\hline & & B & Std. Error & & & & Tolerance & VIF \\
\hline \multirow[t]{3}{*}{1} & (Constant) & .246 & .164 & & 1.499 & .135 & & \\
\hline & PTCV & .112 & .024 & 189 & 4.730 & .000 & .921 & 1.086 \\
\hline & TDNV & .168 & .027 & 251 & 6.157 & .000 & .887 & 1.128 \\
\hline
\end{tabular}



TİNH CẢM CỦA NHÂN VIÊN TẠI CÔNG TY CỔ PHẨN THƯƠNG MẠI SÀI GÒN - SATRA

\begin{tabular}{|l|l|l|l|l|l|l|l|}
\hline DTPT & .136 & .025 & .219 & 5.460 & .000 & .916 & 1.092 \\
\hline DHPT & .145 & .024 & .247 & 5.996 & .000 & .867 & 1.153 \\
\hline TCLD & .120 & .024 & .197 & 4.920 & .000 & .918 & 1.090 \\
\hline DGNV & .156 & .021 & .300 & 7.445 & .000 & .905 & 1.105 \\
\hline QLTH & .092 & .024 & .153 & 3.823 & .000 & .918 & 1.089 \\
\hline
\end{tabular}

Biến số phu thuộc: cam kết tình cảm, $R^{2}$ điều chỉnh $=0,564 ; F($ Sig $)=55,792(0.000)$

Thống kê $F=55,792$ được tính từ $\mathrm{R}^{2}$ có giá trị $\mathrm{Sig}$ rất nhỏ $(\mathrm{Sig} .=0,000)$ chứng tỏ mô hình hồi quy là phù hợp. Cả 7 biến số góp phần giải thích 56,4\% sự biến động của cam kết tình cảm cán bộ nhân viên tại Satra. Các hệ số VIF đều dưới 2,0; điều này chứng tỏ sự cộng tuyến giữa các biến độc lập là rất thấp, phù hợp với giả định trong nghiên cứu này là các biến số là độc lập với nhau.

Kết quả trên cho thấy mức ý nghĩa Sig. của các thành phần là: PTCV (Phân tích công việc), TDNV (Tuyển dụng nhân viên), PTNN (Phát triển nghề nghiệp), DTPT (Đào tạo phát triển), TCLD (Trả công lao động), DGKQ (Đánh giá kết quả nhân viên), THNV (Thu hút nhân viên) là đạt yêu cầu vì có hệ số Sig. $<0,05$, do đó các biến trên có ảnh hưởng đến sự cam kết tình cảm của nhân viên. Từ đó tác giả kết luận rằng các giả thuyết $\mathrm{H}, \mathrm{H} 2, \mathrm{H} 3, \mathrm{H} 4, \mathrm{H} 5, \mathrm{H} 6$ và $\mathrm{H} 7$ được chấp nhận.

\subsection{Phương trình hồi quy tuyến tính bọ̣i}

Phương trình hồi quy tuyến tính dưới sự tác động của 07 thành phần thực tiễn quản trị nguồn nhân lực ảnh hưởng đến cam kêt tình cảm của nhân viên như sau:

\section{CKTC $=0,246+0,112 * P T C V+0,168 *$ TDNV+0,145*DHPT+0,136*DTPT}

\section{$+0,120 *$ TCLD+0,156*DGNV+0,092*QLTH (PT 4.1)}

Trong đó: CKTC là cam kết tình cảm

PTCV là Phân tích công việc

TDNV là Tuyển dụng nhân viên

DHPT là Định hướng phát triển nghề nghiệp

DTPT là Đào tạo phát triển

TCLD là Trả công lao động

DGNV là Đánh giá kết quả nhân viên

QLTH là Quản lý và thu hút nhân viên

\subsection{Tổng kết kết quả kiểm định các giả thuyết}

Kết quả mô hình hồi quy (phương trình 4.1) cho thấy cam kết tỉnh cảm của cán bộ nhân viên tại Satra chịu tác động dương của 7 yếu tố của các thành phần là: PTCV, TDNV, PTNN, DTPT, TCLD, DGKQ, THNV.

Trong đó, các số 0,$112 ; 0,168 ; 0,145 ; 0,136 ; 0,120 ; 0,156 ; 0,092$ là các hệ số hồi quy của các biến thực tiễn quản trị nguồn nhân lực. Nếu hệ số này càng cao thì mức độ ảnh hưởng của biến thực tiễn quản trị nguồn nhân lực đến cam kết tình cảm với công ty càng cao.

\begin{tabular}{|c|c|c|}
\hline & Giả thuyết & Kết quả kiểm định \\
\hline H1 & $\begin{array}{l}\text { Phân tích công việc hiệu quả ảnh hưởng đến mức độ cam kết tình } \\
\text { cảm của cán bộ nhân viên }\end{array}$ & $\begin{array}{l}\text { Chấp nhận } \\
\text { vì Sig. }=0,000<0.05\end{array}$ \\
\hline $\mathrm{H} 2$ & $\begin{array}{l}\text { Tuyển dụng hiệu quả ảnh hưởng đến mức độ cam kết tình cảm của } \\
\text { cán bộ nhân viên }\end{array}$ & $\begin{array}{l}\text { Chấp nhận } \\
\text { Vì Sig.=0,000<0.05 }\end{array}$ \\
\hline $\mathrm{H} 3$ & $\begin{array}{l}\text { Phát triển nghề nghiệp hiệu quả ảnh hưởng đến mức độ cam kết } \\
\text { tình cảm của cán bộ nhân viên }\end{array}$ & $\begin{array}{l}\text { Chấp nhận } \\
\text { vì Sig. }=0,000<0.05\end{array}$ \\
\hline $\mathrm{H} 4$ & $\begin{array}{l}\text { Đào tạo phát triển hiệu quả ảnh hưởng đến mức độ cam kết tình } \\
\text { cảm của cán bộ nhân viên }\end{array}$ & $\begin{array}{l}\text { Chấp nhận } \\
\text { vì Sig.=0,000<0.05 }\end{array}$ \\
\hline H5 & $\begin{array}{l}\text { Trả công lao động hiệu quả ảnh hưởng đến mức độ cam kết tình } \\
\text { cảm của cán bộ nhân viên }\end{array}$ & $\begin{array}{l}\text { Chấp nhận } \\
\text { vì Sig.=0,000<0.05 }\end{array}$ \\
\hline H6 & $\begin{array}{l}\text { Đánh giá nhân viên hiệu quả ảnh hưởng đến mức độ cam kết tình } \\
\text { cảm của cán bộ nhân viên }\end{array}$ & $\begin{array}{l}\text { Chấp nhận } \\
\text { vì Sig.=0,000<0.05 }\end{array}$ \\
\hline $\mathrm{H} 7$ & $\begin{array}{l}\text { Thu hút nhân viên hiệu quả ảnh hưởng đến mức độ cam kết tình } \\
\text { cảm của cán bộ nhân viên }\end{array}$ & $\begin{array}{l}\text { Chấp nhận } \\
\text { vì Sig.=0,000<0.05 }\end{array}$ \\
\hline
\end{tabular}




\subsection{Thảo luận kết quả nghiên cứu}

Thông qua chỉ số giá trị trung bình của các thành phần ảnh hưởng đến cam kết tình cảm tại công ty cổ phẩn Satra mà nhân viên đánh giá ta thấy như sau:

Tuyển dụng nhân viên: Yếu tố này có hệ số beta là 0,168 ảnh hưởng cao nhất đến cam kết tình cảm nhân viên với Satra. Tuy nhiên qua thực tế tại Satra công tác tuyển dụng bị hạn chế, do phải cắt giảm nhân sự theo yêu cầu công việc, đồng thời nếu có tuyển nhân sự thay thế thì do quy trình tuyển dụng của Satra chưa thật sự tuyển đúng người đúng vị trí, một phần do quan hệ mà phải tuyển dụng, cán bộ tuyển dụng chưa đủ phương pháp và kỹ năng để tuyển chọn những nhân viên phù hợp.

Đánh giá kết quả làm việc: Yếu tố thực tiễn đánh giá kêt quả làm việc với cam kết tổ chức có hệ số beta là 0,156 . Điều này giải thích do trong thời gian vừa qua, do hạn chế về mặt hoạt động từ chủ trương tái cơ cấu của ban điều hành công ty nên Satra chưa quan tâm đúng mức đến ban hành các tiêu chuẩn đánh giá công việc, cũng không lấy kết quả làm việc để làm cơ sở cho việc thăng tiến của nhân viên phát triển nghề nghiệp tại Satra.

Định hướng và phát triển nghề nghiệp: Yếu tố này có ảnh hưởng thứ ba đến cam kết tình cảm nhân viên với hệ số beta là 0,145 . Qua thực tế tại Satra công tác định hướng và phát triển nghề nghiệp nhân viên bị lơ là, các cấp lãnh đạo chủ yếu tập trung lo tái cơ cấu mà quên quan tâm đến nguyện vọng của nhân viên, cơ hội thăng tiến bổ nhiệm trong thời gian vừa qua không có, cũng chưa xây dựng mô tả được điều kiện để thăng tiến, chưa quy hoạch nhân sự cho bộ khung nhân lực của Satra.

Đào tạo và phát triển: Yếu tố này có ảnh hưởng thứ tư đến cam kết tình cảm nhân viên có hệ số beta là 0,136 . Chương trình đào tạo, phát triển của Satra phù hợp với yêu cầu của công việc. Công tác thực tiễn đào tạo và phát triển ở Satra vừa qua chưa được đầu tư xứng đáng, chưa chú trọng công tác đào tạo, huấn luyện kỹ năng để nhân viên bán hàng tốt hơn, chương trình đào tạo rất ít diễn ra, đào tạo chủ yếu là tại chỗ, tự kèm cặp nên không thể đào tạo đầy đủ các kỹ năng kiến thức cho nhân viên đáp ứng nhu cầu công việc. Trả công lao động: Yếu tố này có ảnh hưởng thứ 5 đó là thành phần thực tiễn trả công lao động có hệ số beta 0,120 . Qua thực tế ở Satra trong thời gian dài làm ăn thua lỗ, quỹ lương thưởng phúc lợi gần như không tăng, thậm chí phải cắt giảm ngân sách này như lương giảm, thưởng không có ở mỗi kỳ lễ் tết, các chương trình phúc lợi cho nhân viên bị cắt giảm trong nhiều năm qua, thu nhập của nhân viên giảm nên sự cam kết của nhân viên với Satra trong thời gian vừa qua là ở mức thấp.

Phân tích công việc: Yếu tố này tác động mạnh thứ 6 đến cam kết tình cảm nhân viên có hệ số beta là 0,112 . Tình hình hoạt động của Satra cho thấy phân tích công việc chưa bài bản, mặc dù có bảng mô tả công việc nhưng qua thực tế làm việc thì các nhân viên thục hiện đúng, chưa cập nhật những thay đổi công việc của nhân viên, làm ảnh hưởng chung đến hoạt động chung của Satra.

Thu hút nhân viên:Yếu tố này có tác động mạnh thứ 7 đến cam kết tình cảm nhân viên tại Satra có hệ số beta 0,092 ảnh hưởng thấp nhất đến cam kết tình cảm nhân viên Satra. Qua thực tế tại Satra tồn tại môi trường làm việc còn nhiều bức xúc, chưa tạo được sự thân thiện thoải mái trong công việc, có nhiều áp đặt nhân viên và nhân viên chưa thể đóng góp liên quan đến công việc của mình và lãnh đạo cũng thờ ơ trước các đề xuất của nhân viên nhằm cải tiến hoạt động của Satra.

\section{KẾT LUẬN VÀ KIẾN NGH!}

Bằng kỹ thuật phân tích độ tin cậy, phân tích nhân tố khám phá (EFA), và phân tích hồi quy tương quan tuyến tính nhóm tác giả đã xây dựng mô hình nghiên cứu và thang đo đánh giá cam kết tình cảm cán bộ nhân viên tại Satra, theo đó $56,4 \%$ cam kết tình cảm cán bộ nhân viên tại Satra chịu ảnh hưởng của 7 yếu tố theo mức độ ảnh hưởng giảm dần là: Tuyển dụng nhân viên, Đánh giá kết quả làm việc, Định hướng và phát triển nghề nghiệp, Đào tạo và phát triển, Trả công lao động, Phân tích công việc, Thu hút nhân viên.

Về mặt đề xuất kiến nghị, nghiên cứu đã đề xuất cho ban giám đốc công ty Satra các giải pháp nhằm nâng cao công tác quản trị nguồn nhân lực để tăng sự cam kết của cán bộ nhân viên Satra.

Về thực tiễn phân tích công việc: Satra cần xây dựng bảng mô tả công việc nhiệm vụ ở vị trí của từng nhân viên, có bảng mô tả trách nhiệm quyền hạn từng nhân viên, cập nhật bảng mô tả công việc kịp thời, bảng mô tả công việc dễ hiểu. Việc xây dựng cụ thể công việc ở mỗi vị trí, nhằm không dẫm chân công việc của nhau, ai làm việc gì, khi nào hoàn tất, thực hiện việc đó như thế nào. Từ đó nhân viên sẽ thấy được trách nhiệm của mình cũng như tạo sự cam kết gắn bó với Satra ngày càng cao. 
Về thực tiễn tuyển dụng: Satra cần phải có chính sách tuyển dụng đúng người và thưởng xuyên sát hạch nhân viên để có điều chỉnh công việc cho phù hợp với kỹ năng và năng lực thực tế sau một thời gian làm việc tại Satra. Satra nên thiết kế một chương trình tuyển dụng chặt chẽ và chuyên nghiệp hơn nhằm làm cho nhân viên đánh giá cao quy trình tuyển dụng của Satra nghĩa là họ hài lòng với kết quả tuyển dụng mà Satra đã dành cho họ và họ sẽ yên tâm cống hiến hơn vì họ đã tìm ra được Satra là một tổ chức đã hiểu rõ năng lực của họ.

Về định hướng và phát triển nghề nghiệp: Khi một ứng viên được tuyển dụng vào làm việc, Satra cần phổ biến chính sách thăng tiến và phát triển nghề nghiệp rõ ràng để nhân viên có mục tiêu và phương hướng phấn đấu trong sự nghiệp của mình thông qua các tiêu chí như Satra có chương trình định hướng nghề nghiệp rõ ràng, cấp trên quan tâm tìm hiểu nguyện vọng nghề nghiệp của nhân viên, mô tả điều kiện để thăng tiến, chính sách thăng tiến công bằng.

Về đào tạo và phát triển: Satra cần xây dựng chương trình đào tạo phải có tính thực hành cao, huấn luyện đầy đủ kiến thức và kỹ năng để nhân viên đáp ứng ngay nhu cầu công việc để phục vụ khách hàng tốt hơn, và công việc đào tạo phải được thực hiện thường xuyên nhằm bổ sung kiến thức kịp thời cho nhân viên, cập nhật quy định quy trình quy chế, kiến thức pháp luật mới để làm cho nhân viên không bị động trước những thay đổi thị trường.

Về trả công lao động: Satra phải chú trọng việc xây dựng hệ thống tiền lương, thưởng, phúc lợi tốt nhằm thúc đẩy nhân viên gẳn bó hơn với FPTS. Cơ chế trả công lao động linh hoạt, hợp lý, xứng đáng với công việc và đánh giá đúng hiệu quả công tác của nhân viên sẽ góp phần không nhỏ để giữ chân nhân viên giỏi. Về đánh giá công việc: Satra nên xây dựng quy trình đánh giá kết quả làm việc cụ thể, rõ ràng và công bằng nhằm giúp ích cho nhân viên nâng cao chất lượng công việc, nhằm có kết hoạch đào tạo và phát triển nghề nghiệp của mỗi nhân viên và được lãnh đạo phản hồi tích cực mức độ hoàn thành công việc. Việc thực hiện đánh giá công việc chính xác rõ ràng sẽ làm cho người lao động cam kết gắn bó với Satra ngày càng cao.

Về thu hút nhân viên: Satra cần tạo ra cho nhân viên mình không gian để họ tự chủ công việc miễn sao đạt hiệu quả cao nhất, để từ đó thu hút nhân viên vào việc ra các quyết định của họ cùng với tập thể lãnh đạo Satra, hơn nữa họ thực hiện công việc theo cách quen thuộc và được đưa ra các quyết định liên quan đển công việc của mình thì nhân viên cảm thấy hứng thú làm việc hơn và gắn bó với nghề nhiều hơn.

\section{TÀI LIỆU THAM KHẢO}

Danh mục tài liệu Tiếng Việt

1. Trần Kim Dung (2011), Quản trị nguồn nhân lưc, Nhà Xuất bản Thống kê.

2. Nguyễn Thanh Hội (2007), Quản trị học, Nhà Xuất bản Thống kê.

3. Phan Văn Kha (2007), Đào tạo và sử dụng nhân lực trong nền kinh tế thị trường ở Việt Nam, Nhà Xuất bản Giáo dục.

\section{Danh mục tài liệu tiếng Anh}

1.John P. Mayer \& Catherine A.Smith (2000), "HRM practices and organizational commitment: Test of a mediation model", Canadian Journal of Administrative Sciences, 17(4):319- 325

2. Mowday, R.T., Steers, R. and Porter, L.W., (1979), "The measurement of organizational commitment", Journal of Vocational Behavior, 14: 224-

3. Meyer, J. P., Stanley, D. J., Herscovitch, L., and Topolnyutsky, L. (2002).

"Affective, continuance, and normative commitment to the organization: A metaanalysis of antecedents, correlates, and consequences", Journal of Vocational Behavior, 61, 20-52.'

Ngày nhận bài: 02/01/2019

Ngày chấp nhận đăng: 05/05/2019 